\title{
A Transmissão Geracional da Violência na Relação Conjugal
}

\author{
Tatiana Camargo Sant'Anna ${ }^{1}$ \\ Maria Aparecida Penso \\ Universidade Católica de Brasília
}

\begin{abstract}
RESUMO - Trata-se de um estudo de caso, cujo objetivo foi investigar a transmissão geracional da violência e papéis estereotipados de gênero a partir da Teoria Familiar Sistêmica e da Teoria de Gênero, com um casal vítima de violência conjugal. Os instrumentos foram Entrevista do Ciclo de Vida Familiar e Genograma. As informações foram analisadas utilizando a epistemologia construtivo-interpretativa. As análises apontaram que os cônjuges vivenciaram padrões relacionais violentos em suas famílias de origem, com papéis estereotipados de homem e mulher, baseados no modelo patriarcal, e que as vivências de cada cônjuge em suas famílias de origem, influenciou o casal, em seu relacionamento, tanto na estereotipia de cada papel quanto na forma de lidar com as negociações e os conflitos conjugais.
\end{abstract}

Palavras chave: violência conjugal, transmissão geracional, Teoria Familiar Sistêmica, gênero, relações conjugais

\section{Intergenerational Transmission of Violence in Marital Relations}

\begin{abstract}
The present study is a case study of a couple with a history of marital violence. Its objective was to investigate the intergenerational transmission of violence and stereotyped gender roles using the Systemic Family Theory and Gender theory. The instruments were the Interview of Family Lifecycle and the Genogram. The data were analyzed using the constructiveinterpretative epistemology. The analyzes showed that the spouses experienced violent relational patterns in their families of origin, with stereotypical roles of men and women, based on the patriarchal model and that the experiences of each spouse in their families of origin, influenced the couple in their relationship, both the stereotype of each paper as in dealing with negotiations and marital conflict.
\end{abstract}

Keywords: marital violence, intergenerational transmission, Systemic Family Theory, gender, marital relations

A violência conjugal é um fenômeno multideterminado e complexo, que envolve muitos fatores: entre eles, as vivências dos papeis masculinos e femininos na sociedade e na família. Nesse sentido, o tema deste artigo é a transmissão geracional da violência conjugal e a naturalização dos papéis estereotipados de gênero de um casal vítima de violência conjugal, utilizando como referencial teórico a Teoria Familiar Sistêmica com respaldo na Teoria de Gênero.

O pensamento sistêmico privilegia o inter-relacional, enfatizando o contexto (tempo e espaço) no qual o sujeito encontra-se inserido (Vasconcellos, 2002). Avança de um modelo linear de causa e efeito para um modelo circular de padrão interacional, além de considerar o indivíduo como um ser social que influencia o contexto em que se encontra inserido, ao mesmo tempo em que é influenciado pelo mesmo (Minuchin, 2008).

A Teoria de Gênero discute as desigualdades de gênero, pontuando a importância do respeito e de condições igualitárias sociais e políticas entre homens e mulheres, entendendo que ambos são sujeitos ativos e participantes no processo de desenvolvimento, independentemente de seus papéis sexuais. Postula que a masculinidade encontra-se, socialmente, associada ao poder e à violência, e que a lógica patriarcal ordena às mulheres que se mantenham submissas,

1 Endereço para correspondência: Rua 08,Chácara 214, casa 17, Vicente Pires , Brasília, DF, Brasil. CEP: 72.007-010.E-mail: tatysantanna@, hotmail.com dependentes e inferiores, diminuindo suas próprias qualidades e exaltando às do companheiro, cumprindo assim a expectativa do social (Araújo, 2002; Bandeira, 2008; Saffioti, 1999).

A violência conjugal, a cada dia, ganha maior visibilidade social no Brasil e no mundo. (Ferres-Pérez \& Bosch-Fiol, 2014; Medrado \& Lyra, 2003; Saffioti, 2001). Em 1980, o Instituto Brasileiro de Geografia e Estatística (IBGE) constatou que $63 \%$ das agressões cometidas contra as mulheres ocorriam no âmbito das relações domésticas (Fontana \& Santos, 2001). Desse período até o momento atual, outras pesquisas apontam para o elevado índice de violência contra mulheres, que chega, em alguns casos, a sua exterminação por homicídio. Pesquisa de 2013, do DataSenado, em municípios brasileiros com mulheres com 16 anos ou mais, mostrou que $99 \%$ das mulheres entrevistadas sabem da existência da Lei 11.340/06, mais conhecida como Lei Maria da Penha. (Brasil, 2006). Dados dessa pesquisa apontaram que 13,5 milhões de mulheres já foram vítimas de algum tipo de agressão e destas $31 \%$ ainda convivem com o agressor, entre as quais $14 \%$ destas ainda sofrem algum tipo de violência. Entre as mulheres que já sofreram violência, $65 \%$ foram agredidas pelo seu parceiro, $13 \%$ por ex-companheiros e $11 \%$ por parentes consanguíneos e cunhados. Entre as mulheres agredidas, 40\% procuraram ajuda após a primeira agressão, mas $15 \%$ dos casos não 
buscaram qualquer tipo de auxilio, seja por intermédio de uma rede social ou por denúncia (Brasil, 2013).

A promulgação da Lei Maria da Penha configurou a violência contra a mulher como crime de maior potencial ofensivo. Posteriormente, em 2015 foi promulgada a Lei $\mathrm{n}^{\mathrm{o}} 13.104 / 2015$ que diz respeito ao feminicídio (Brasil, 2015). Feminicídio ou femicídio são termos designados para conceituar o homicídio de mulheres em razão do conflito de gênero, ou seja, pelo simples fato de ser do sexo feminino, e que envolve, dessa forma, ódio ou menosprezo pela condição de ser mulher. De acordo com o Instituto de Pesquisa Econômica Aplicada (IPEA), 40\% dos homicídios mundiais, de mulheres, são cometidos por um parceiro íntimo. De 2001 a 2011, estima-se que, no Brasil, ocorreram mais de 50.000 feminicídios. Mesmo após a criação da lei Maria da Penha, a pesquisa realizada pelo IPEA constatou que não houve redução das taxas anuais de mortalidade. Os dados apontam que, no período de 2001 a 2006, a taxa anual de mortalidade por 100 mil mulheres brasileiras foi de 5,28 e de 5,22. Registraram-se, no período de 2009 a 2011, 13.071 feminicídios, o que equivale a uma taxa de 4,48 óbitos por 100 mil mulheres. Isso significa que, nesse período, ocorreram, no Brasil, mais de 5 mil mortes de mulheres a cada ano, 427 a cada mês e 15 a cada dia. Dessas mortes, $29 \%$ ocorreram no domicílio da vítima, $31 \%$ em via pública e $25 \%$ em ambientes de saúde (Brasil, 2015).

Os conceitos de violência na relação conjugal se apresentam, tanto na literatura quanto no ambiente jurídico e social, a partir de diferentes expressões, tais como, violência de gênero, violência familiar, violência intrafamiliar e violência doméstica. A violência de gênero se refere às relações de violência entre homem e mulher, mas também, entre dois homens ou até entre duas mulheres. Violência familiar considera os laços consanguíneos, referindo-se aos indivíduos de uma mesma família, seja ela extensa ou nuclear, cuja violência ocorre no interior do domicílio familiar ou fora dele (Araújo, 2002; Saffioti, 1999, 2004). O termo violência doméstica é designado aos membros (familiares ou não) que convivem no mesmo espaço doméstico. Por fim, a violência conjugal é aquela que é cometida contra a mulher por seu parceiro ou contra o homem por sua parceira, no contexto em que existe, entre o casal, um relacionamento afetivo ou sexual independente deste ser legalizado ou não. Importante destacar que a terminologia violência conjugal foi criticada pelas feministas por dar a ideia de agressões mútuas, sendo que, para elas, seria mais adequado utilizar os termos violência contra a mulher ou violência de gênero para descrever a violência que acontece na relação conjugal (Rosa \& Falcke, 2014).

Apesar das críticas feministas, neste artigo, será utilizado o termo violência conjugal por ser uma expressão de uso comum na sociedade e no contexto acadêmico por entender que o fenômeno da violência que acontece dentro de um relacionamento conjugal, dá-se de forma interacional e pelo fato de seu significado estar tipificado na Lei Maria da Penha, primeira lei a abordar, de forma específica, a violência conjugal. A referida lei reconhece o ciclo da violência, entendendo que esta tem uma dinâmica que deve ser encarada em caráter extraordinário e interpretada sob a perspectiva de pressupostos teóricos diferentes dos que eram adotados anteriormente a esta lei (Campos, 2010). Ela pode ocorrer tanto no espaço doméstico quanto urbano e abarca todas as formas de violência, seja ela física, moral, sexual ou psicológica (Narvaz \& Koller, 2006a; Saffioti, 1999, 2004).

Diante dos dados apresentados anteriormente, pode-se concluir que a violência contra a mulher é um problema social e de saúde pública, sendo importante entender as dinâmicas familiares e sociais que atribuem os significados dos papéis sociais a homens e mulheres e como estes são transmitidos nas famílias através das gerações. A esse respeito, os trabalhos de Bucher-Maluschke (2003a), Ribeiro e Bareicha (2008), Gomes (2005) e Flood e Pease (2009) apontam para a perpetuação da violência nas relações familiares, em um processo de transmissão geracional do comportamento violento. Rosa e Falcke (2011) pontuam que crianças que sofreram experiências de violência na infância podem vir a ter experiências semelhantes na vida adulta. Segundo as autoras, fatores como abandono materno, abuso de substâncias por parte dos pais e/ou repetição de comportamentos violentos são fatores de risco que podem favorecer a perpetuação da violência. Por outro lado, as autoras afirmam existirem fatores de proteção, tais como modelos amorosos saudáveis, tratamento psicoterápico e rede de apoio bem constituída, que interrompem a transmissão da violência. Assim, considera-se importante pesquisar sobre a violência na relação conjugal, a maneira como ela é passada de geração a geração, a forma como ela influencia a definição de papeis, valores e crenças compartilhadas. Também é importante considerar como as desigualdades existentes quanto às questões de gênero influenciam e demarcam a construção dos relacionamentos conjugais.

\section{Relações Conjugais e Familiares na Perspectiva da Teoria Sistêmica e da Teoria de Gênero}

A família, para a Teoria Sistêmica, constitui-se como a matriz de identidade de seus membros, proporcionando o sentimento de pertencimento, mas também permitindo a separação e individuação de cada um (Costa, 2010). Para Féres-Carneiro (2003), a noção de família pressupõe a interiorização de vivências, percepções e valores que serão repassados para as demais relações, sejam elas de qual tipo forem. A maneira como os papéis, as negociações e as resoluções de conflitos ocorreu na família de origem assim como a forma como as regras foram definidas no decorrer das relações são herdadas e internalizadas pelos filhos, além de serem transmitidas às gerações seguintes (Bowen, 1978; Bucher-Maluschke, 2003b; Papero, 1998). Assim, as vivências familiares influenciarão as decisões e escolhas amorosas de seus membros, que se encontram diretamente fundamentadas em uma representação simbólica, construída pela família, bem como pelo contexto sociocultural em que esses membros encontram-se inseridos. Os movimentos de separação e individuação irão influenciar a forma como o sujeito ajusta seus ideais pessoais à vivência da conjugalidade, o período de transição do desenvolvimento humano, que modifica sua realidade e a de sua família de origem, estando relacionado não só ao seu Ciclo de Vida 
Individual, mas, também, ao Ciclo de Vida Familiar (Carter \& McGoldrick, 2001).

O conceito de Ciclo de Vida Familiar pressupõe que a família também está organizada em um processo evolutivo das suas relações. Carter e McGoldrick (2001) dividem o Ciclo de Vida Familiar em seis estágios, sendo que cada um tem como objetivo proporcionar uma mudança no status familiar. São eles: 1) Saindo de casa: jovens solteiros; 2) A união de famílias no casamento: o novo casal; 3) Famílias com filhos pequenos; 4) Famílias com adolescentes; 5) Lançando os filhos e seguindo em frente e; 6) Famílias no estágio tardio da vida. Cada estágio é composto por papéis a serem desempenhados distintamente pelos membros da família, tarefas a serem cumpridas e processos emocionais a serem resolvidos. Portanto, as mudanças que ocorrem no status familiar são necessárias para que os membros e a família possam prosseguir em seu desenvolvimento.

A transição para a fase da união do casal pode ser uma das mais complexas, em razão das ambivalências existentes na sociedade moderna a respeito do papel do casal e também porque cada um dos cônjuges, ao se unir ao outro, traz consigo as influências sociais e culturais que sofreu em sua família de origem (Carter \&McGoldrick, 2001; Féres-Carneiro \& DinizNeto, 2008). Por outro lado, as vivências ao longo do Ciclo de Vida Familiar possibilitam que algumas transformações, no decorrer da vivência da relação conjugal, modifiquem a maneira como um membro do casal age com o outro, e vice-versa, proporcionando mudanças no comportamento de ambos de forma a acomodar as interações familiares, sejam elas funcionais ou não (Carter \& McGoldrick, 2001; Falcke \& Féres- Carneiro, 2011). Assim, se, em uma família, as relações são caracterizadas pelo autoritarismo e rigidez, não existindo outros fatores externos ou internos de proteção que modifiquem esse padrão, podem ocorrer repetições das relações de violência. Quando isso acontece, seus membros possivelmente buscarão resolver seus problemas e estabelecer relações conjugais semelhantes às vivenciadas e internalizadas no seio familiar, podendo, por exemplo, estabelecer relacionamentos que têm a violência como base. $\mathrm{O}$ ciclo da violência pode ser rompido se existirem fatores de proteção no contexto familiar, tais como, a rede social de apoio, a coesão familiar e a resiliência dos cônjuges, que proporcionem a ressignificação das experiências vividas e a transformação dos padrões relacionais da família. (Ramos \& Oliveira, 2008; Rosa \& Falcke, 2011).

Portanto, é importante considerar os pressupostos da Teoria Familiar Sistêmica nos estudos e análises dos casos de violência conjugal, uma vez que ela prioriza as diferentes interrelações dos subsistemas, reconhece as relações de complementaridade e considera a família como um espaço privilegiado de proteção (Ribeiro \& Albuquerque, 2008). Além disso, essa teoria considera que os valores socioculturais, os significados dos papéis de homem e mulher são transmitidos e atualizados em um processo definido na Terapia Familiar como transmissão multigeracional (Bowen, 1978; Penso, 2003).

Contudo, a perspectiva de gênero permite a compreensão de que, dentro da família, existem diferenças de poder nos seus subsistemas e entre os participantes de cada subsistema. Socialmente, a mulher, "caracterizada" por sua fragilidade, emocionalidade e um histórico de submissão, torna-se vítima frequente da opressão e discriminação social, econômica e cultural (Lima, Buchele \& Clímaco, 2008). Também é necessário considerar que seus papéis e funções são construídos nas estruturas sociais da família (Swain, 2010). A perspectiva patriarcal violenta, que foi, ao longo dos séculos, incentivada e mantida pela sociedade, influenciou e influencia, diretamente, as relações familiares.

Autoras como Diniz (2011) e Falcke, Rosa e Madalena (2012) associam os aspectos da transmissão multigeracional da violência conjugal com as questões de gênero, pois estas demarcam a maneira como as dinâmicas das relações se estruturam e como são vivenciadas pelos membros do sistema familiar. Para as autoras, os valores socioculturais interferem no sistema familiar e nos relacionamentos de seus membros influenciando a formação do indivíduo e os aprendizados que lhe foram transmitidos sobre os papéis de homem e de mulher e seus significados. Esses ditos sobre o que é ser homem e ser mulher encontram-se atrelados ao que é permitido ou proibido socialmente quanto à forma como cada papel deve desempenhar a fim de cumprir as tarefas que foram pré-estabelecidas (Haddock, Zimmerman \& Phee, 2000). Esse raciocínio pode ser aplicado na compreensão da violência conjugal, pois o relacionamento do casal sofre influência, entre outros fatores, das questões de gênero. Vale ressaltar, que além dos papéis esteriotipados, a Teoria de Gênero descreve a importância do estabelecimento de condições igualitárias, em termos sociais e políticos, entre homens e mulheres, pois compreende que ambos são sujeitos ativos e participantes no processo de desenvolvimento social e histórico da humanidade, o que independeria do sujeito nascer homem ou mulher (Goodrich \& Silverstein, 2005). No entanto, é preciso considerar que a violência conjugal também ocorre em razão de outros fatores, como a falta de apoio social e a ausência de fatores de proteção na família.

Tendo como base, os conceitos apresentados acima, o objetivo deste artigo é investigar como os aspectos transgeracionais da violência e dos papéis estereotipados de gênero podem influenciar o relacionamento de um casal vítima de violência conjugal que teve aplicação da Lei Maria da Penha.

\section{Método}

Esta é uma pesquisa qualitativa, baseada na perspectiva construtivo-interpretativa proposta por González-Rey (2005), que considera o conhecimento como uma produção da realidade. Trata-se de um estudo de caso, que, segundo Gil (1999), tem como característica investigar de forma profunda e intensa casos múltiplos ou um caso único, possibilitando, ao pesquisador, compreender os fenômenos complexos atuais do pesquisado, dentro de sua realidade. O projeto foi aprovado pelo comitê de ética em pesquisa da Universidade Católica de Brasília, com o número 181/2011.

\section{Participantes}


Participou desta pesquisa um casal com história de violência conjugal que foi integrante de um grupo de acompanhamento psicossocial em razão da aplicação da Lei Maria da Penha. Os cônjuges Bruna ${ }^{1}, 37$ anos, e Jorge, 45 anos, ambos com ensino médio completo, pertencem à classe média baixa, vivem em união consensual há 12 anos e não possuem filhos dessa união.

\section{Instrumentos}

Entrevista do ciclo de vida familiar. Explora o processo desenvolvimental da família ao longo do seu Ciclo de Vida Familiar e amplia o olhar sobre o casal, a partir da observação do relacionamento intergeracional (Penso, 2003). A entrevista do Ciclo de Vida Familiar, elaborada por Penso (2003), baseada nas fases do ciclo de vida descritas por Carter e McGoldrick (2001), busca entender a história da família no decorrer do tempo e como esta resolveu o processo emocional de transição de cada fase e conseguiu cumprir as tarefas específicas necessárias para avanço no tempo de forma funcional.

Genograma. Representação gráfica e eficiente que possibilita recolher e organizar dados multigeracionais da família, bem como verificar a sua composição, estrutura e padrões de relacionamento e funcionamento (Carter \& McGoldrick, 2001) Nesta pesquisa, foi explorada, principalmente, a transmissão geracional de aspectos ligados à conjugalidade e aos comportamentos violentos presentes nas famílias de origem de cada cônjuge.

\section{Procedimentos de Coleta}

O casal que participou da pesquisa já havia participado de um grupo psicossocial para casais inseridos na Lei $n^{\circ}$ 11.340/06 (Lei Maria da Penha), devido à confirmação da violência conjugal cometida pelos companheiros contra suas companheiras. O grupo foi realizado em uma Promotoria de Justiça localizada em uma Região Administrativa do Distrito Federal. Os casais que fizeram parte do grupo foram contatados e convidados a participarem da pesquisa. Porém, dos cinco casais que foram contatados, quatro não aceitaram serem sujeitos da pesquisa, ou haviam se separado de seus cônjuges ou não foram localizados. Assim, apenas um casal concordou em participar da pesquisa e a este foi explicado todo o procedimento da pesquisa, juntamente com a garantia das condições éticas que envolve a mesma. Ambos os cônjuges assinaram o Termo de Consentimento Livre e Esclarecido.

Com esse casal, foram realizados três encontros, sendo os dois primeiros com a presença de ambos os cônjuges. No primeiro, realizou-se a entrevista do Ciclo de Vida Familiar; no segundo, a confecção do genograma de Jorge; e, no terceiro, a entrevista de confecção do Genograma de Bruna. $\mathrm{O}$ terceiro encontro se deu sem a presença do marido por este ter esquecido a data e o horário combinados. A opção pela

1 Para resguardar o sigilo das identidades dos participantes, foram utilizados nomes fictícios. realização dos genogramas em separado ocorreu em razão da ausência do marido no terceiro encontro. Os encontros foram realizados, por solicitação dos participantes, em sua residência, sendo todos gravados em áudio e transcritos na íntegra.

\section{Procedimentos de Análise}

A análise das entrevistas e do genograma permitiu o levantamento de indicadores e a construção das Zonas de Sentido, conforme proposta da epistemologia construtivointerpretativa de González-Rey (2005). Os indicadores são elementos que, por intermédio da interpretação do pesquisador, adquirem significados e representam um momento interpretativo com a finalidade de dar sentido ao não observável. São categorias com características explicativas que, ao serem produzidas, constituem-se em instrumentos para construção das Zonas de Sentido (Gonzáles-Rey, 2005).

As Zonas de Sentido são construções do pesquisador, sendo influenciadas por suas posturas teóricas e práticas, possibilitando uma construção processual de caráter único na produção de conhecimento e informação (González-Rey, 2005; Passos \& Penso, 2009). Neste artigo, serão discutidas duas Zonas de Sentido: O relacionamento conjugal nas familias de origem: violência contra as mulheres e filhos e A herança familiar e o relacionamento conjugal atual: o (re) encontro com a violência.

\section{Resultados}

Serão apresentadas informações sobre a historia do casal, buscando contemplar as histórias de suas famílias de origem e a história do casal.

\section{As Famílias de Origem de Bruna e Jorge}

Os pais de Bruna são do interior de um estado do nordeste e encontram-se casados. Como pode ser observado no genorama, desse relacionamento nasceram oito filhos, sendo Bruna a primogênita. Seu pai sempre trabalhou com agricultura e administrava as finanças da família. Sua mãe era costureira e usava o que ganhava para as pequenas necessidades dos filhos, além de auxiliar seu esposo na lavoura, quando necessário. Bruna afirma que a relação dos pais sempre foi muito conflituosa, relatando lembranças de episódios de agressão por parte de seu pai contra sua mãe (verbais e físicas) e de violências físicas de seus pais para com ela e seus irmãos quando crianças (Figura 1).

Os pais de Jorge também são do nordeste, encontramse casados e têm oito filhos, sendo Jorge o mais novo. Jorge possui outros dois irmãos resultantes de relações extraconjugais do pai, mas estes não fazem parte do ciclo de relacionamento de sua família. Seu pai trabalhava como cobrador de ônibus e conheceu sua mãe em uma de suas viagens. Iniciaram o namoro sem o consentimento dos avôs maternos de Jorge, até que sua mãe engravidou e os dois se casaram. Seu pai viajava muito a trabalho e sua mãe ficava em 
casa sempre muito doente, com uma doença, sem diagnóstico, que a fazia ficar acamada e internada durante longos períodos. Nessas ocasiões seus irmãos mais velhos responsabilizavamse pelos afazeres domésticos e pelo cuidado com os irmãos

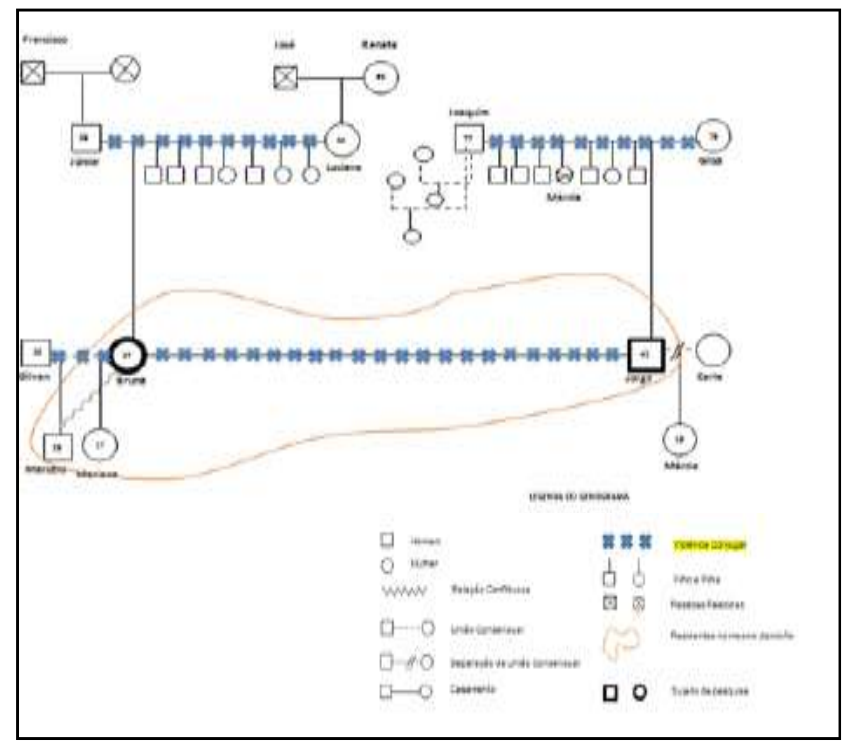

Figura 1. Genograma de Bruna e Jorge

mais novos. Seus pais brigavam muito porque seu pai fazia uso de álcool e sempre traiu sua mãe. Quando embriagado, irritava a sua mãe, que chegava a agredi-lo fisicamente, como demonstrado no Genograma (Figura 1).

\section{A história do Casal - Bruna e Jorge}

Bruna e Jorge estão casados há doze anos e não possuem filhos dessa relação. Ambos tiveram um relacionamento anterior que resultou em filhos. $\mathrm{Na}$ ocasião da pesquisa, conviviam na mesma residência Jorge, Bruna e os dois filhos de Bruna. A filha de Jorge residia com sua ex-esposa, não havendo contato entre eles.

O casal se conheceu no ambiente de trabalho. Jorge relata que, quando conheceu Bruna e percebeu seu comportamento reservado, interessou-se e a convidou para um encontro. Bruna, por sua vez, explica que, em um primeiro momento, não aceitou os convites de Jorge, mas que a insistência dele e sua forma atenciosa e carinhosa fizeram com que ela cedesse aos seus apelos. O casal conta que sempre teve, desde o namoro, o plano de ter uma casa, um carro e uma família.

Relatam que os conflitos conjugais foram frequentes desde o namoro quando empurrões e tapas já faziam parte da rotina do casal. No inicio da relação, as desavenças eram devido aos ciúmes e as desconfianças de Bruna para com Jorge, pois ele tinha um comportamento boêmio, marcado por infindáveis passeios noturnos e ingestão de álcool. Após 6 meses de namoro, casaram-se. Ambos relatam que, com o passar dos anos, a violência foi se intensificando até chegar ao seu ápice, após 8 anos de casamento, que proporcionou a denuncia e a intervenção da justiça.
Para Bruna, o relacionamento melhorou depois da intervenção da justiça. Quando se deparam com um conflito, Jorge tenta contornar a situação, sendo mais carinhoso e iniciando as conversas entre eles. Nessas situações, ela se posiciona de forma arredia, mas, em um segundo momento, cede e conversa com Jorge.

\section{Discussão}

\section{O Relacionamento Conjugal nas Famílias de Origem: Violência contra as Mulheres e Filhos.}

Esta Zona de Sentido discute o modelo de relacionamento conjugal, afetivo e familiar que cada um dos membros do casal obteve de suas famílias de origem. Busca identificar semelhanças e diferenças entre esses modelos, na perspectiva de que a formação do novo casal é influenciada pelas vivências e pelos aprendizados que cada um dos cônjuges teve em seu sistema familiar de origem (Féres-Carneiro, 2003; Silva, Correa, \& Lopes, 2010). Será apresentada a partir dos seguintes tópicos: 1) O modelo de relacionamento conjugal das famílias de origem de Bruna e Jorge; e 2) O relacionamento conjugal violento e os filhos.

\section{O modelo de relacionamento conjugal das famílias de origem de Bruna e Jorge.}

Jorge e Bruna tiveram modelos conjugais tradicionais em suas famílias de origem. Na família de Jorge, seu pai era responsável por prover financeiramente esposa e filhos, viajava muito a trabalho, e sua mãe desempenhava o papel de cuidadora dos filhos e da casa: "Meu pai só trabalhava e minha mãe dentro de casa cuidando da gente" (Jorge). Não havia compartilhamento entre o casal quanto às tomadas de decisões referentes ao lar e aos filhos. O poder de decisão era do pai, que detinha a autoridade dentro de sua família: "Era ele. Meu pai sempre falou alto. Quando falava, todo mundo murchava. Inclusive minha mãe" (Jorge).

$\mathrm{Na}$ família de Bruna, o modelo de relacionamento conjugal era semelhante, sendo composto por um homem provedor e detentor do poder sobre os assuntos da família e uma mulher submissa que acatava as decisões do marido. Seu pai não permitia abertura para qualquer questionamento sobre suas resoluções: "Porque meu pai, ele era assim muito... A mulher nunca tem vez. Nem de falar. Faz só lavar, passar e cozinhar" (Bruna). Sua mãe é descrita como amorosa, sentimental, passiva e submissa: "A minha mãe sempre era mais carinhosa assim" (Bruna). Cabia a ela, a função de organizar a casa e educar os filhos pela sua capacidade de ser mais doce, caprichosa e devota ao seu esposo e as suas crias (Almeida, 2007).

Tratava-se, portanto, de uma divisão tradicional dos papéis, na qual cabe ao homem prover financeiramente a família, exercendo o domínio sobre todos, e à mulher cuidar da casa e dos filhos, ficando restrita ao lar, executando tarefas domésticas, sem poder de decisão sobre a vida familiar 
(Bandeira, 2009; Goodrich, Rampage, Elman, \& Halstead, 1990; Narvaz \& Koller, 2006b; Nascimento \& Trindade, 2010; Saffioti, 2004; Walters, 1994). Nesse contexto, tanto os pais de Bruna quanto de Jorge apresentavam dificuldades na negociação de normas e regras, comprometendo a reciprocidade e a igualdade entre os cônjuges, aspectos importantes nas relações conjugais, por possibilitar a flexibilidade a respeito dos papéis sexuais e sociais entre homem e mulher (Mosmann, Lomando, \& Wagner, 2010; Silva, Strey, \& Magalhães, 2011; Walsh, 2005).

Em ambas as famílias, as atribuições de homem e mulher encontravam-se fixadas no estereótipo sobre esses dois papéis e as regras eram definidas pelos homens, sem espaço para negociação entre os cônjuges: "A mulher nunca tem vez. Nem de falar. Só lavar, passar e cozinhar. Pra eles, assim, mulher era isso" (Bruna). "Minha mãe dizia que ele não pensava nos filhos e em ninguém, queria só saber de farra, de cachaça, de bebedeira" (Jorge). Trata-se de papeis estereotipados sobre o que era permitido ao masculino e negado ao feminino (Diniz, 2011; Saffioti, 2004)

O pai de Jorge e o de Bruna posicionavam-se perante a família tomando as decisões individualmente, baseadas nas realizações de seus desejos, sem pensar no bem-estar de sua família, destituindo sua esposa da possibilidade de auxiliálos ou negociarem possíveis resoluções para os conflitos conjugais e para um melhor funcionamento do sistema familiar. Como demonstrado no Genograma (Figura 1), a mãe de Jorge fazia tentativas de se impor contra as decisões de seu marido. Porém, na impossibilidade do diálogo, agredia-o fisicamente e se agredia, adoecendo e ficando acamada. A mãe de Bruna, por sua vez, rendia-se às decisões do marido, permanecendo em uma posição de submissão. Tais situações possibilitaram a instalação de padrões disfuncionais de relação em torno de ganhar ou perder poder (Minuchin,1999).

Quanto à demonstração de afeto, predominava, nas famílias e Bruna e Jorge, o modelo patriarcal, em que os homens não demonstram afeto, por seu senso de identidade estar baseado na realização de objetivos econômicos e sociais, mais do que nas relações de afetividade (Papp, 1995). O pai de Bruna nunca demonstrou sinais de afetividade para com sua mãe. No entanto, esta, em alguns momentos, demonstrava seu afeto: "Minha mãe era tipo, assim, que procurava tá ao lado, a fazer um carinho. [...] eu nunca vi meu pai fazer isso com ela. Era sempre agressão física e verbal" (Bruna). Jorge, por sua vez, também não se lembra de demonstrações de afeto e carinho entre seus pais no ambiente familiar: "Que eu me lembre, não" (Jorge). Duas mulheres vivendo situações parecidas, mas reagindo de forma diferente: uma que conseguia demonstrar seu afeto em relação ao companheiro, a despeito do seu comportamento violento, e a outra (mãe de Jorge) que, sem recursos para enfrentar o marido e violentada por ele, adoecia.

Segundo Diniz, Portella, Ludermir, Valença e Couto, (2007), a violência pode afetar a saúde física das mulheres, fazendo surgir alguns sintomas de adoecimento visíveis. Pesquisa realizada por Figueiredo, Penso e Almeida (2012) com mulheres vítimas de violência conjugal mostrou que estas apresentavam problemas de saúde e psicológicos decorrentes da violência sofrida.
Em resumo, a relação conjugal dos pais de Bruna e Jorge foi marcada por papéis rígidos e estereotipados, com regras não negociadas e impostas pelos homens da família, autoridade centrada na figura masculina, havendo ausência de demonstrações de afetividade e de negociação. Tratase de dois sistemas conjugais que estabelecem modelos disfuncionais de relacionamento, prejudicando também o sistema familiar. Tal contexto contribuiu para a naturalização de papeis estereotipados de gênero nas famílias de origem de Bruna e Jorge e sua repetição na história do casal formado por eles, perpetuando a violência na relação conjugal.

\section{O Relacionamento Conjugal Violento dos Pais de Bruna e Jorge e os Filhos}

Falcke e Féres-Carneiro (2011) e Bucher-Maluschke (2003a) afirmam que, ao manter uma relação direta com o sistema parental, os filhos são espectadores de situações vividas por seus pais sobre como estes se relacionam. Isso significa que o tipo de vínculo amoroso que os pais cultivam entre si e para com os filhos servirá como modelo para futuras gerações.

O relacionamento conjugal dos pais de Bruna foi permeado pela violência praticada pelo seu pai contra sua mãe, presenciada por ela e seus irmãos, impotentes frente a situação: "Corda, pedaço de pau e porrada mesmo. Eu acho que nunca se resolveu. Era assim, eles brigavam, ele batia nela e ela ficava toda machucada. Ele agredia ela na nossa frente, né? A gente não podia fazer nada. Chorava, ficava cada um no seu lugar" (Bruna).

Essa violência perdurou por um longo período e quando os filhos, já crescidos tentaram intervir para proteger a mãe, foram expulsos de casa: "ele parou de bater na minha mãe acho que tem uns 12 anos, que foi quando meus irmãos revoltaram contra ele e reagiram, e assim ele expulsou todos de casa." (Bruna). Isso mostra a rigidez do sistema familiar, que não consegue produzir mudanças internas ao longo do seu Ciclo de Vida Familiar (Carter \& McGoldrick, 2001).

Jorge afirma ter presenciado algumas desavenças entre seus pais que resultaram em agressões físicas mútuas, mas que estas eram sempre iniciadas por sua mãe, que não aceitava os comportamentos do companheiro: "Tinha (desavenças) porque ele bebia muito. Quando ficava bêbado chegava ligando o som na maior altura. Ela ficava louca da cabeça" (Jorge).

A violência presente na relação conjugal foi repetida na educação dos filhos. Bruna relata que a educação dela e dos irmãos foi marcada por agressões físicas ou verbais, princípios e valores rígidos sobre certo e errado. "Apanhava muito. Tanto do meu pai quanto da minha mãe. É, tipo assim, me dava uma ordem pra fazer aquilo e se não fizesse aquilo rápido e de imediato, já era motivo de apanhar" (Bruna). Seus pais utilizavam, então, o que Bucher-Maluschke (2004) chama de aval da violência como educação e respeito, a fim de controlar e instruir os filhos. Ramos e Oliveira (2008) afirmam que, quando os pais utilizam o abuso de poder para disciplinar, corrigir e educar seus filhos, eles perpetuam o modelo patriarcal em que os filhos são propriedades dos pais e usam a violência na relação com o filho, por acreditarem que 
essas ações resultarão na formação de indivíduos melhores futuramente. Rosa e Lira (2012) afirmam que, ainda nos dias atuais, a violência física é, muitas vezes, considerada natural na educação dos filhos, sendo legitimada e justificada, servindo como modelo para as gerações seguintes. No entanto, tal prática denota a crença de que aquele que tem mais poder, no caso os pais, pode abusar de tal situação em nome da obediência e da postura de posse sobre o outro (Ravazzola, 2007).

A mãe de Bruna igualava-se ao marido no uso da violência, perpetuando um ciclo perverso e complicado: "Minha mãe, assim, ela brigava com meu pai. O que o meu pai fazia com ela, ela tipo descontava na gente" (Bruna). Portanto, podemos inferir que a mãe de Bruna, sem nenhum recurso para lidar com a situação conjugal, agredia os filhos, descontando neles a raiva que sentia do marido e perpetuando a violência nas relações familiares (Bucher-Maluschke, 2003a; Falcke et al., 2012; Ribeiro \& Bareicha, 2008;).

No caso de Jorge, por seu pai ser viajante e ausentar-se por longos períodos de sua residência, a educação dos filhos era de responsabilidade de sua mãe. À medida que os filhos cresciam, os mais velhos passavam a cuidar dos mais novos, organizando-se para sobreviverem, principalmente porque a mãe era portadora de uma doença sem diagnóstico, o que a obrigava a ficar acamada por meses, pois sentia muitas dores e, por várias vezes, com crises intensas, ficava internada no hospital: "Os médicos até desenganaram dela. [...] a pele dela soltava, ficava babando" (Jorge). Falcke, Oliveira, Rosa e Bentancur (2009) esclarecem que a forma como os indivíduos vivenciaram, na infância, experiências de maustratos, abusos, negligência, violência física e psicológica, seja recebendo ou presenciando-os na relação com os pais, pode ser um fator de risco para a perpetuação da violência. Ramos e Oliveira (2008) pontuam que famílias cujos pais vivem situações de violência podem apresentar dificuldades emocionais, despreparo e imaturidade na educação para com os filhos.

A situação familiar descrita por Jorge não gerava a segurança de que os filhos necessitavam para se desenvolverem de forma saudável, uma vez que a maneira como seu pai se posicionava proporcionava instabilidade emocional para a família, pois, além de ausentar-se por questões de trabalho, gastava tudo o que ganhava para satisfazer seus desejos pessoais: "Torrava (o dinheiro). Ele não pensava no amanhã, achava que não ia envelhecer. Ganhava hoje, gastava hoje. [...] era muito mulherengo [...] eu me lembro, ele capotou dois caminhão por conta de cansaço e cachaça" (Jorge).

As práticas educativas das famílias de origem de Bruna e Jorge apresentam semelhanças no que se refere à definição dos papéis estereotipados e regras rígidas atribuídas ao homem e à mulher. Contudo, Jorge teve um pai omisso enquanto Bruna teve um pai presente, apesar de ser dominador e violento. Os relatos de Jorge mostram a negligência de seus pais na relação com os filhos, que também é uma forma de violência prejudicial ao desenvolvimento psicossocial dos filhos. No caso de Jorge, era uma violência velada em forma de omissão frente às necessidades emocionais e psicológicas (Delfino, Alves, Sagim, \& Venturini, 2005).
Sendo frutos de relações conjugais permeadas por violência, sofrendo violência por parte de seus pais e não contando com outras pessoas internas ou externas a família que pudessem representar fatores de proteção, Jorge e Bruna parecem naturalizar a violência como um padrão de relacionamento. Essas vivências nas famílias de origem também parecem ter influenciado as futuras escolhas de seus parceiros, fazendo com que estabelecessem relações conjugais baseados na agressão conjugal. (Falcke \& FéresCarneiro, 2011).

\section{A Herança Familiar e o Relacionamento Conjugal Atual: $O$ (re)Encontro com a Violência}

Esta Zona de sentido discute como a herança familiar influenciou o relacionamento atual do casal, que tem a presença da violência como um dos seus aspectos. Bruna e Jorge se conheceram no ambiente de trabalho e iniciaram o relacionamento amoroso, com a expectativa de que este fosse diferente daquele vivido, por cada um, anteriormente. Jorge se apresentou para Bruna como alguém paciente e atencioso, e, em contrapartida, Bruna mostrou-se comportada e independente financeiramente: "Foi o jeito dela. Eu chegava na empresa e as meninas ficavam tudo doida e eu não dava moral pra ninguém. Aí eu cheguei lá um dia e tem gente nova. Aí me interessei, né? É, ela não dava em cima de mim." (Jorge). Bruna, por sua vez, explica que, em um primeiro momento, não aceitou os convites de Jorge, mas que a insistência dele e a forma atenciosa e carinhosa que ele demonstrava fizeram com que ela cedesse aos seus apelos e o relacionamento amoroso foi se consolidando: "Sempre falei pra ele que, 'se um dia eu namorar com você ou ficar com você, não vai ser assim, ficar hoje, termina amanhã'. Meu caso é: 'se quer ficar comigo tem que ser relacionamento sério, senão é melhor a gente parar por aqui'. Ai ele: 'Eu quero um relacionamento sério com você" "(Bruna).

No entanto, ambos relataram haver discórdias desde o início da relação. Para Bruna, o jeito boêmio de Jorge era a maior causa das desarmonias entre o casal: "O namoro... Ai foi meio conturbado... ele era muito mulherengo, ele bebia e eu não gostava. E eu não concordava, nunca gostei de farra" (Bruna). Jorge relatou que, desde o namoro, Bruna sempre desconfiou da sua fidelidade e que muitas desavenças foram devido as suas crises de ciúmes, mesmo ele procurando convencê-la de que ela não tinha motivos para ter ciúmes: "Ai eu falei pra ela: 'a partir do momento que escolhi morar com ela, viver com ela, meu passado morreu'... Então eu canso de dizer pra ela: 'minha vida é só ela'. Minha vida se resume a ela, aos filhos dela, que são meus filhos também, não é?" (Jorge).

Jorge mencionou que, ao se casar, esperava que Bruna diminuísse seus ciúmes, fosse uma esposa mais acolhedora e entendesse e aceitasse seu comportamento extrovertido e comunicativo. Jorge posiciona-se, assim, de acordo com o modelo masculino de sua família de origem, no sentido de ser permitido, justificado e incentivado socialmente ao homem ter comportamentos diferenciados, pelo simples fato de ter nascido homem (Diniz, 2011; Saffioti, 1999, 2004). Desse modo, ele percebe como normais seus comportamentos de 
infidelidade, agressividade, uso de álcool e imposição de seus desejos, pois esse é o modelo que aprendeu com seu pai, ao qual sua mãe sem forças para reagir, adoecia. No entanto, as reações da mãe de Bruna foram diferentes da mãe de Jorge. Ela não adoeceu, ao contrário, confrontou as atitudes de seu companheiro, o que ocasionou diversos conflitos entre o casal. Nesse sentido, Bruna repetia na relação com Jorge o que aprendeu com sua mãe, pois reagia ao seu comportamento.

Ao serem questionados como eram negociadas as decisões da vida do casal, Jorge explicou que as decisões eram e ainda são tomadas em conjunto: "Avisava. Sempre avisei" (Jorge). Bruna contestou o marido dizendo que Jorge sempre decidiu tudo sozinho e, até hoje, decide por si e, no final, apenas comunica o resultado a ela: "Não, tipo assim, eu vou fazer isso e pronto e acabou. Não importava se eu tava de acordo ou não" (Bruna). Bruna afirmou que sempre fez diferente do marido, perguntando sua opinião, mas que ele nunca lhe apoiou: "Ele nunca me dava uma força ou uma opinião positiva, sempre negativa. Pra ele, eu nunca era capaz, nunca sou capaz de fazer alguma coisa" (Bruna).

Portanto, a negociação não é vista da mesma forma para os cônjuges e essas divergências provocam conflitos que levam à emersão da violência física. De acordo com Giddens (1993), dentro da dinâmica conjugal, os membros negociam seus papéis e essa negociação só é possível se houver um grau de flexibilidade dos pares em relação aos papéis sexuais e sociais de ambos. De acordo com o autor, o oposto do diálogo, nessa perspectiva, é a violência, exatamente o que acontece com Bruna e Jorge.

Os conflitos entre o casal, que, inicialmente, culminavam em discussões, foram se intensificando gradualmente, gerando as agressões mútuas, em um processo de reciprocidade da violência (Granjeiro, 2012), como relatou Bruna: "Eu começava a cobrar, a falar... e ele é assim, se você começar a cobrar e a falar ele já se irrita, ele já vai em cima. E isso me irrita muito" (Bruna). Jorge tentou amenizar a fala da esposa: "eu só botava o dedo na cara dela, sabe? E ela pegava meu dedo e queria quebrar" (Jorge). Porém, ela se manteve discordante e finalizou dizendo: "eu pegava o dedo dele e puxava o dedo pra traz e mandava ele tirar, e ele não tirava. Ai quando eu fazia isso, ele já me dava um tapa. Sempre começava assim.... ele é assim. Ele sempre cria uma situação que te tira do sério" (Bruna).

Em razão de suas histórias familiares, conforme discutido na primeira Zona de Sentido, Bruna e Jorge parecem ter internalizado que é por intermédio da violência que se obtêm respeito. $\mathrm{O}$ modo como se apropriaram da violência, portanto, está vinculado à transmissão geracional do comportamento violento, com os quais tiveram contato em sua infância, enquanto observantes do modelo conjugal original e enquanto filhos (Bucher-Maluschke, 2003a). Parece que faltaram fatores de proteção, como relações com a família extensa, com outros sistemas conjugais ou com o contexto social que pudessem modificar a concepção de que o modelo violento era o único possível. Segundo Bowen (1978), modelos vinculares originários podem fornecer modelos implícitos para o funcionamento da dinâmica familiar futura.

O comportamento descrito pelo casal corresponde às colocações de Granjeiro (2012) sobre a agressão mútua.
Segundo a autora, o estabelecimento de conflitos de casais que têm em sua relação a agressão mútua é uma forma de o homem manter a relação de maneira tradicionalista (mulher dependente e submissa) ou uma tentativa da mulher de distribuição igualitária de poder. Esse pensamento está de acordo com o observado na relação do casal estudado, pois Bruna, quando se posicionava, esbarrava na resistência de Jorge e, como eles não conseguiam negociar suas questões, os conflitos surgiam e transformavam-se em agressões físicas, das quais Bruna saia perdendo: "só que no final quem saia mais machucada era eu... porque, tipo... era assim, eu sou uma pessoa que eu prefiro me machucar do que machucar o outro. Mas quando eu vier a machucar o outro é porque não dá mais pra segurar" (Bruna).

O casal relatou ter ocorrido um episódio que exemplifica a questão da reciprocidade da violência. Jorge contou que, certa vez, saiu para encontrar com uns amigos para "tomar umas" e que, ao retornar para casa, Bruna o recebeu enfurecida, com o tom de voz alterado, e começou a falar da sua indignação em relação ao fato de ele ter voltado para casa tarde da noite e que, por esse motivo, era para ele retornar ao local onde estava, pois tinha certeza de que ele a estava traindo. Ele negou as acusações de Bruna diversas vezes, tentando explicar para ela que suas suspeitas de traição eram infundadas, o que foi em vão. Diante dos fatos, Jorge resolveu dizer que, uma vez que ela não acreditava em sua palavra, então ele havia decidido seguir seu conselho e retornar ao local onde estava anteriormente. Após essa fala, Bruna o atacou e o agrediu. Ele, por sua vez, revidou: "Eu revidei. Ela dava um tapa, eu dava outro. 'Você quer bater? Vamo bater. Se você gosta de bater é porque você gosta de apanhar" " (Jorge).

No entanto, há uma contradição entre os relatos de Bruna e Jorge, como pode ser observado na versão de Bruna sobre o mesmo acontecimento: "Foi aí que eu reagi. Ele me espancou bastante, né? E eu esperei ele terminar. Eu esperei ele cansar de me espancar pra depois eu reagir. E aí eu peguei uma faca e fui pra cima dele. Ai ele me deu uma rasteira e eu sai rolando no chão e ele me chutando. E eu com a faca na mão enquanto ele tava me chutando e eu rolando no chão. Eu furei as pernas dele" (Bruna).

De acordo com Falcke e Wagner (2011), a dinâmica da violência no casal quase sempre revela ser um processo cíclico, relacional e progressivo, no qual vários homens e mulheres permanecem por anos. Segundo as autoras, esse processo foi denominado de Ciclo da Violência por Leonore Walker em 1978.

Em resumo, Bruna e Jorge, ao se unirem, trazem consigo experiências e vivências negativas das suas famílias de origem e dos relacionamentos anteriores e, ao concretizarem seu relacionamento amoroso, fizeram-no com a esperança de que algo diferente acontecesse e que fosse melhor do que aquilo que vivenciaram anteriormente. Entretanto não conseguiram alcançar esse objetivo, pois, ao se depararem com situações conflituosas, não conseguiram negociar, culminando no aparecimento de diversos tipos de violência em sua dinâmica conjugal, semelhante ao que ambos vivenciaram e presenciaram em suas famílias de origem. A violência que, no início da relação era caracterizada por desavenças, gradualmente foi se intensificando até chegar ao 
seu ápice, com situações de violência física muito intensa, que culminou na denúncia à justiça.

\section{Considerações Finais}

As informações levantadas nas entrevistas e no Genograma mostraram que as configurações familiares vividas nas famílias de origem de Bruna e Jorge eram permeadas por valores patriarcais. Mostravam-se presentes papéis estereotipados e tradicionalistas para homens e mulheres, sendo os homens detentores de poder sobre tudo e sobre todos, provedores financeiros da família, mas distantes afetivamente; ficando a cargo das mulheres o papel de submissas, cuidadoras dos filhos, da casa e do marido, além de serem responsáveis pela expressão da afetividade para com marido e filhos.

A divisão dos papéis era rígida e conservadora, sendo as regras do relacionamento conjugal das famílias de origem de Bruna e Jorge determinadas de acordo com os desejos do pai-patriarca. Nesse sentido, a conjugalidade presenciada por Jorge e Bruna em suas famílias de origem foi permeada por diversas violências, seja por parte do pai de Bruna para com a sua mãe (violência física e psicológica), seja por parte do pai de Jorge (enquanto violência psicológica e negligência), o que provocava em sua esposa duas reações: ou ela agredia fisicamente o marido ou ficava doente.

Essa violência cometida contra as mulheres também atingia os filhos, seja como expectadores ou como vítimas efetivas de tal violência. Tais vivencias nortearam suas escolhas conjugais, fazendo com que revivessem as situações presenciadas em suas famílias de origem, mesmo com o desejo de construírem relações baseadas em premissas diferentes. A diferença é que o aumento da violência levou a uma intervenção da justiça, que fez cessar a violência física e deu ao casal a chance de participarem de um grupo de atenção psicossocial em que puderam refletir sobre sua relação e buscar transformar seu padrão de funcionamento. Isso é relatado por eles quando são questionados sobre como estava o relacionamento no momento da pesquisa, quando se percebeu um casal buscando achar formas de se relacionar melhor e permanecer junto, transformando a sua história e a si mesmos.

Cabe assinalar que se trata de um estudo de caso, com um casal que participou de um grupo psicossocial, o que possibilitou mudanças na sua forma de funcionamento e também a construção de outras interpretações sobre sua relação.

\section{Referências}

Almeida, L. S. de (2007). Mãe, cuidadora e trabalhadora: As múltiplas identidades de mães que trabalham. Revista do Departamento de Psicologia. UFF, 19(2), 411-422.

Araújo, M. F. (2002). Violência e abuso sexual na família. Psicologia em Estudo, 7(2), 3-11.

Bandeira, L. A. (2008). Contribuição da crítica feminista à ciência. Estudos Feministas, 16(1), 207-230.
Bandeira, L. A (2009). Três décadas de resistência feminista contra o sexismo e a violência feminina no Brasil: 1076 a 2006. Sociedade e Estado, 24(2), 401-438.

Bowen, M. (1978). Family therapy in clinical practice. Nova York: Jason Aronson.

Brasil. (2006). Lei 11.340 de 7 de agosto de 2006. Lei Maria da Penha. Retrieved from http://www.planalto.gov.br/CCIVIL/ Ato2004-2006/2006/Lei/L11340.htm>.

Brasil. Secretaria de Transparência. DataSenado. (2013). Violência doméstica e familiar contra a mulher. Brasília: Senado Federal. Retrieved from http://www.senado.gov.br/senado/datasenado/ pdf/datasenado/DataSenado-Pesquisa-Violencia_Domestica contra_a_Mulher_2013.pdf.

Brasil. (2015). Lei 13.104 de 09 de março de 2015. Lei do Femicídio. Retrieved from http://www.planalto.gov.br/ ccivil_03/_Ato2015-2018/2015/Lei/L13104.htm.

Bucher-Maluschke, J. S. N. F. (2003a). Família, lócus de vivências: Do amor à violência. In T. Féres-Carneiro (Org.), Família e casal: Arranjos e demandas contemporâneas (pp.169-199). São Paulo: Loyola.

Bucher-Maluschke, J. S. N. F. (2003b). Relações conjugais em transformações e sofrimento psíquico: Uma sociedade em transição. In I. Costa, A. F. Holanda, F. Martins, \& M. I. Tafuri (Orgs.), Ética, linguagem e sofrimento (pp. 295-305). Brasília: Positiva.

Bucher-Maluschke, J. S. N. F. (2004). Vínculo, afetividade e violência: Desafios para a família e a sociedade. In G. Maluschke, J. S. N. F. Bucher-Maluschke, \& K. Hermanns (Orgs.), Direitos humanos e violência: Desafios da ciência e da prática (pp. 157-170). Fortaleza: Fundação Konrad Adenaueur.

Campos, C. H. (2010). Lei Maria da Penha: Um novo desafio jurídico. In F. R. Lima \& C. Santos (Orgs.), Violência doméstica: Vulnerabilidades e desafios na intervenção criminal e interdisciplinar (pp. 21-37). Rio de Janeiro: Lumen Juris.

Carter, B., \& McGoldrick, M. (2001). As mudanças no ciclo de vida familiar: Uma estrutura para a terapia familiar $\left(2^{\mathrm{a}} \mathrm{ed}\right.$. , A.V. Veronese, Trad.). Porto Alegre: Artes Médicas. (Trabalho original publicado em 1989)

Costa, L. F. (2010). A perspectiva sistêmica para a clínica da família. Psicologia: Teoria e Pesquisa, 26(número especial), 95-104.

Delfino, V., Alves, Z. M. M. B., Sagim, M. B., \& Venturini, F. P. (2005). A identificação da violência doméstica e da negligência por pais de camada médias populares. Revista Texto, Contexto e Enfermagem, 14, 38-46.

Diniz, D. (2011). Estereótipos de gênero nas cortes internacionais - Um desafio à igualdade: Entrevista com Rebecca Cook. Estudos Feministas, Florianópolis, 19(2), 451-462.

Diniz, S., Portella, A. P., Ludermir, A. B., Valença, O., \& Couto, M. T. (2007). Prevalência da violência contra a mulher por parceiro íntimo em regiões do Brasil. Revista de Saúde Pública, 41(5), 797-807.

Falcke, D., \& Féres-Carneiro, T. (2011). Reflexões sobre a violência conjugal - Diferentes contextos, múltiplas expressões. In A. Wagner (Org.), Desafios psicossociais da família contemporânea - Pesquisas e reflexões (pp. 72-85). Porto Alegre: Artmed.

Falcke, D., Oliveira, D. Z., Rosa, L. W., \& Bentancur, M. (2009). Violência conjugal: Um fenômeno interacional. Contextos Clínicos, 2(2), 81-90. 
Falcke, D., Rosa, L. W., \& Madalena, M. (2012). Violência familiar: Rompendo o ciclo transgeracional e seguindo em frente. In M. N. Baptista \& M. L. M. Teodoro (Orgs.), Psicologia de família - Teoria, avaliação e intervenção (pp. 127-136). Porto Alegre: Artmed.

Falcke, D. \& Wagner, A. (2011). A violência na conjugalidade: Possibilidades de intervenção. In T. Féres-Carneiro (Org.), Casal e Família: Conjugalidade, parentalidade e psicoterapia (pp. 149-160). São Paulo: Casa do Psicólogo.

Féres-Carneiro, T. (2003). Separação: Doloroso processo de dissolução da conjugalidade. Estudos de Psicologia, 8(3), 367-374.

Féres-Carneiro, T., \& Diniz-Neto, O. (2008). De onde viemos? Uma revisão histórico conceitual da psicoterapia de casal. Psicologia, Teoria e Pesquisa, 29(4), 487-496.

Ferres-Pérez, V., \& Bosch-Fiol, E. (2014). Gender violence as a social problem: Spain atitudes and acceptability. Sex Roles, 70, 506-521.

Figueiredo, D. G., Penso, M. A., \& Almeida, T. M. C. (2012). Violência conjugal sob a ótica de mulheres no Itapoã. In M. A. Penso \& T. M. C. Almeida (Orgs.), Direitos e conflitos psicossociais: Ações e interfaces disciplinares (pp. 57-74). São Paulo: Roca.

Flood, M., \& Pease, B. (2009). Attitude to violence against women. Trauma, violence \& abuse, 10(2), 125-142.

Fontana, M., \& Santos, S. F. (2001). Violência contra a mulher. In Rede Nacional Feminista de Saúde e direitos reprodutivos (Org.), Saúde da mulher e direitos reprodutivos: Dossiês (pp. 101-128). Retrieved from http:www.redesaude.org.br

Giddens, A. (1993). A transformação da intimidade: Sexualidade, amor e erotismo nas sociedades modernas. São Paulo: Unesp.

Gil, A. (1999). Métodos e técnicas de pesquisa social. São Paulo: Atlas.

Gomes, I. C. (2005). Transmissão psíquica transgeracional e violência conjugal: Um relato de caso. Boletim de Psicologia, 55(123), 177-188.

González-Rey, F. (2005). Pesquisa qualitativa em psicologia: Caminhos e desafios. São Paulo: Pioneira Thomson Learning.

Goodrich, T. J., Rampage, C., Ellman, B., \& Halstead, K. (1990). Terapia feminista da família (R. M. Garcia, Trad.). Porto Alegre: Artes Médicas. (Trabalho original publicado em 1988)

Goodrich, T. J. \& Silverstein, L. B. (2005). Now you see it, now you don't: Feminist training in family therapy. Family Process, 44(3), 267-281.

Granjeiro, I. (2012). Agressão conjugal mútua: Justiça restaurativa e Lei Maria da Penha. Curitiba: Juruá.

Haddock, S. A.; Zimmerman, T. S., \& Phee, D. M. (2000). The power equity guide: Attending to gender in family therapy. Journal of Marital and Family Therapy, 26(2), 153-170.

Lima, D. C., Buchele, F., \& Clímaco, D. A. (2008). Homens, gênero e violência contra a mulher. Revista Saúde e Sociedade, 17(2), 69-81.

Medrado, B., \& Lyra, J. (2003). Nos homens, a violência de gênero. In Brasil (Org.), Programa de prevenção, assistência e combate à violência contra a mulher - Plano Nacional (pp. 21-26). Brasília: Secretaria Especial de Políticas para as Mulheres.

Minuchin, S. (1999). A estrutura. In P. Minuchin, J. Colapino, \& S. Minuchin (Orgs.), Trabalhando com famílias pobres (M. F. Lopes, Trad., pp. 19-37). Porto Alegre: Artes Médicas. (Trabalho original publicado em 1998)
Minuchin, S. (2008). O encontro terapêutico In S. Minuchin, W. Lee, \& G. M. Simon (Orgs.), Dominando a terapia familiar (G. Klein, Trad., pp. 99-122). Porto Alegre: Artmed. (Trabalho original publicado em 1996)

Mosmann, C. P. , Lomando, E., \& Wagner, A. (2010). Coesão e adaptabilidade conjugal em homens e mulheres hetero e homossexuais. Barbaroi (33), 135-152.

Narvaz, M. G., \& Koller, S. H. (2006a). Mulheres vítimas de violência doméstica: Compreendendo subjetividades assujeitadas. Revista PSICO, 37(1), pp. 7-13.

Narvaz, M. G., \& Koller, S. H. (2006b). Metodologias feministas e estudo de gênero articulando pesquisa, clínica e política. Psicologia em Estudo, 11(3), 647-654.

Nascimento, C. R. R., \& Trindade, Z. A. (2010). Criando meninos e meninas: Investigação com famílias de um bairro de classe popular. Arquivos Brasileiros de Psicologia, 62(2), 187-200.

Papp, P. (1995). Prisioneiros do papel sexual. In M. Andolfi, C. Angelo, \& C. Saccu (Orgs.), O casal em crise (S. F. Foá, Trad., pp. 147-154). São Paulo: Summus.

Papero, D. V. (1998). A teoria sobre os sistemas familiares de Bowen. In M. Elkaim (Org.), Panorama das terapias familiares (pp. 71-100). São Paulo: Summus.

Passos, L., \& Penso, M. (2009). O papel da comunidade na aplicação e execução da justiça penal. Brasília: Esmpu.

Penso, M. A. (2003). Dinâmicas familiares e construção identitária de adolescentes envolvidos em atos infracionais e drogas (Tese de doutorado não publicada). Universidade de Brasília, Brasília, DF, Brasil.

Ramos, M. E. C., \& Oliveira, K. D. (2008). Transgeracionalidade percebida nos casos de maus-tratos. In M. A. Penso \& L. F. Costa (Orgs.), A transmissão geracional em diferentes contextos: Da pesquisa à intervenção (pp. 99-122). São Paulo: Summus.

Ravazzola, M. C. (2007). Violência nas relações familiares. Pensando Famílias, 11(1), 11-28.

Ribeiro, M. A., \& Albuquerque, M. (2008). Separação e recasamento: aspectos transgeracionais dos novos arranjos familiares. In M. A. Penso \& L. F. Costa (Orgs.), A transmissão geracional em diferentes contextos: Da pesquisa à intervenção (pp. 224-250). São Paulo: Summus.

Ribeiro, M. A., \& Bareicha, I. C. (2008). Investigando a transgeracionalidade da violência intrafamiliar. In M. A. Penso \& L. F. Costa (Orgs.), A transmissão geracional em diferentes contextos: Da pesquisa à intervenção (pp. 251-281). São Paulo: Summus,

Rosa, L. W., \& Falcke, D. (2011, Noviembre). Rompendo o ciclo de violência doméstica. Anais do III Congreso Internacional de Investigación y Práctica Profesional en Psicología XVIII. Jornadas de Investigación Séptimo Encuentro de Investigadores en Psicología del MERCOSUR. Facultad de Psicología - Universidad de Buenos Aires, Buenos Aires, pp. 218-222.

Rosa, L. W., \& Falcke, D. (2014). Violência conjugal: Compreendendo o fenômeno. Revista SPAGESP, 15(1), 17-32.

Rosa, E. M., \& Lira, M. O. de S. C. e (2012). Intrafamiliar violence against children and adolescents: Support and overcoming network. Journal of Human Growth and Development, 22(2), 246-252.

Saffioti, H. I. B. (1999). Já se mete a colher em briga de marido e mulher. São Paulo em Perspectiva, 13(4), 82-91. 
Saffioti, H. I. B. (2001). Contribuições feministas para o estudo da violência de gênero. Cadernos Pagu, 16, 115-136.

Saffioti, H. I. B. (2004). Gênero, patriarcado e violência. São Paulo: Fundação Perseu Abramo.

Silva, J. A., Strey, M. N., \& Magalhães, A. S. (2011). Sobre a motivação para a conjugalidade. In S. Minuchin, M. P. Nichols, \& W. Lee (Orgs.), Famílias e casais: Do sintoma ao sistema (J. M. Dellamora, Trad., pp. 32-46). Porte Alegre: Artmed.

Silva, I. M. da, Corrêa, C., \& Lopes, R. de C. S. (2010). Em busca da "cara-metade": Motivações para a escolha do cônjuge. Estudos de Psicologia (Campinas), 27(3), 383-391.
Swain, T. N. (2010). O grande silêncio: A violência da diferença sexual. In C. Stevens, K. C. T. Brasil, T. M. C. Almeida, \& V. Zanello (Orgs.), Gênero e feminismos: Convergências (in) disciplinares (pp. 35-48). Brasília: Líbris.

Vasconcellos, M. J. E. (2002). Pensamento sistêmico: O novo paradigma da ciência. São Paulo: Papirus.

Walsh, F. (2005). Reconexão e reconciliação: Uma ponte sobre águas turbulentas. In Walsh, F. Fortalecendo a resiliência familiar (pp.265-298). São Paulo: Roca.

Walters, M. (1994). Uma perspectiva feminista da terapia de família. In R. J. Perelberg \& A. C. Miller (Eds.), Os sexos e o poder nas famílias (M. C. B. Fernandes, Trad., pp. 27-46). Rio de Janeiro: Imago. (Trabalho original publicado em 1990) 